Methods: We collected data from consecutive patients diagnosed with SSc according to EULAR/ACR criteria and from healthy controls $(\mathrm{HC})$ matched for age and sex. Patients underwent BIVA for the assessment of fat mass (FM), free fat mass (FFM), total body water (TBW), extracellular water (ECW), body cellular mass (BCM), basal metabolic rate (BMR) and $\mathrm{ECM} / \mathrm{BCM}$ ratio, an early index of protein catabolism. Data included anthropometric and clinical features, Body Mass Index (BMI) and specific organ involvement with particular attention to gastrointestinal symptoms. Laboratory parameters, including haemoglobin and albumin levels, were also collected. Additionally, patients completed the UCLA GIT 2.0 questionnaire.

Results: Data from 50 SSc patients ( $92 \%$ female; mean age $61.1 \pm 12.5$ years; mean disease duration $13.4 \pm 10.2$ years) and from $50 \mathrm{HC}$ were compared. BIVA revealed that SSc patients presented a significant reduction in BMR, BCM and ECW values compared to $\mathrm{HC}(\mathrm{p}<0.001$ for all). The former also exhibited a higher ECM/BCM ratio $(p<0.001)$. No significant differences regarding FM, FFM, TBW and BMI were found between the two groups. Among the cohort of SSc patients, a direct correlation was found between age and ECW $(p=0.001 ; \rho=0.473)$ and between disease duration and FM ( $p=0.023 ; \rho=0.325)$, whereas age inversely correlated with BMR $(p=0.012 ; \rho=-0.357)$. Patients with anaemia and/or hypoalbuminemia had significantly reduced BMR, BCM and TBW values; those with hypoalbuminemia also had elevated ECW levels $(p=0.001)$. No other significant associations with BIVA values were found among the laboratory findings and among the gastrointestinal complaints. Results showed relevant interrelations between BIVA parameters and the SSc-related involvement of different organs, e.g. digital ulcers, interstitial lung disease and pulmonary arterial hypertension (See Table 1). In addition, a higher skin involvement inversely correlated with FM ( $p=0.038 ; p=-0.387)$. The only correlation that emerged from the UCLA GIT 2.0 questionnaire was the inverse relationship between TBW and GIT-reflux ( $p=0.017 ; p=-0.385)$. Four patients died during the study: they had significantly lower BMR and BCM, with an increased ECW.

Table 1.

\begin{tabular}{|c|c|c|c|c|c|}
\hline & $\begin{array}{l}\text { Ongoing digital } \\
\text { ulcers }\end{array}$ & $\begin{array}{l}\text { History of digital } \\
\text { ulcers }\end{array}$ & $\begin{array}{l}\text { Interstitial lung } \\
\text { disease }\end{array}$ & $\begin{array}{l}\text { Pulmonary arterial } \\
\text { hypertension }\end{array}$ & $\begin{array}{l}\text { Heart } \\
\text { involvement }\end{array}$ \\
\hline FM & $\mathrm{p}=0.006$ & ns & $\mathrm{p}=0.042$ & ns & ns \\
\hline FFM & $\mathrm{p}=0.019$ & $\mathrm{p}=0.046$ & ns & ns & ns \\
\hline TBW & $\mathrm{p}<0,001$ & ns & $\mathrm{p}=0.007$ & ns & ns \\
\hline ECW & $\mathrm{ns}$ & ns & $\mathrm{p}=0.015$ & $\mathrm{p}=0.004$ & $p=0.02$ \\
\hline BCM & $p=0.01$ & $\mathrm{p}=0.047$ & $\mathrm{p}=0.016$ & $\mathrm{p}=0.013$ & $p=0.03$ \\
\hline BMR & $\mathrm{p}=0.002$ & $\mathrm{p}=0.036$ & $\mathrm{p}=0.004$ & $\mathrm{p}=0.015$ & $\mathrm{~ns}$ \\
\hline $\mathrm{ECM} / \mathrm{BCM}$ & ns & ns & $\mathrm{p}=0.034$ & ns & ns \\
\hline
\end{tabular}

Conclusion: BIVA has shown that SSc patients have a worse nutritional status than HC. The parameters obtained with BIVA in SSc patients correlate with serological malnutrition markers (haemoglobin and albumin), with various organ-specific SSc manifestations (cardiopulmonary involvement and digital ulcers) and with mortality. BIVA could therefore play a role in the prognostic stratification of SSc patients.

Disclosure of Interests: None declared

DOI: 10.1136/annrheumdis-2020-eular.2436

\section{SAT0312 SUBCLINICAL ATHEROSCLEROSIS IN SYSTEMIC SCLEROSIS AND RHEUMATOID ARTHRITIS: A COMPARATIVE MATCHED-COHORT STUDY}

P. Baniotopoulos ${ }^{1}$, E. Pagkopoulou ${ }^{2}$, S. Soulaidopoulos ${ }^{2}$, A. Sandoo ${ }^{3,4}$, N. Katsiki ${ }^{5}$, A. Karagiannis ${ }^{5}$, K. Douglas ${ }^{4}$, A. Garyfallos ${ }^{2}$, G. Kitas ${ }^{4,6}$ T. Dimitroulas ${ }^{2} .{ }^{1}$ GKT School of Medical Education, King's College London, London, United Kingdom; ${ }^{2} 4$ th Department of Internal Medicine, Hippokration Hospital, Aristotle University of Thessaloniki, Thessaloniki, Greece; ${ }^{3}$ School of Sport, Health and Exercise Sciences, Bangor University, Bangor, United Kingdom; ${ }^{4}$ Russells Hall Hospital, Dudley Group NHS FT, Department of Rheumatology, Bangor, United Kingdom; ${ }^{5}$ 2nd Propedeutic Department of Internal Medicine, Hippokration Hospital, Aristotle University of Thessaloniki, Thessaloniki, Greece; 6 University of Manchester, Arthritis Research UK Centre for Epidemiology, Manchester, United Kingdom

Background: Systemic autoimmune inflammatory disorders confer a higher risk of cardiovascular (CV) disease leading to increased morbidity and mortality compared to the general population. CV risk in Systemic Sclerosis (SSc) has not been studied so extensively as in other diseases, such as Rheumatoid Arthritis (RA), and the real impact of CV disease on SSc prognosis remains unknown. Surrogate markers of atherosclerosis namely carotid intima media thickness (cIMT) and pulse wave velocity (PWV) are impaired in some but not all studies in SSc patients.

Objectives: The aim of the study was to investigate the prevalence of subclinical atherosclerosis assessed by cIMT and PWV between two well-characterized SSc and RA cohorts.
Methods: Consecutive SSc patients attending the Scleroderma Clinic were compared with RA patients recruited in the Dudley Rheumatoid Arthritis Co-morbidity Cohort (DRACCO), a prospective study examining CV burden in RA. Cardiovascular risk was assessed using the QRisk3 and cIMT, Augmentation Index (Alx75) and central systolic and diastolic blood pressure were measured in all participants. Propensity score matching, was utilized to select patients from the two cohorts with similar demographic characteristics, CV risk factors (smoking hypertension, obesity, dyslipidemia, diabetes) and inflammatory load. Unpaired t-test and Chi-square test of independence were applied.

Results: Fifty five age- and sex-matched SSc and RA patients with similar distribution of $\mathrm{CV}$ risk factors were included. No difference was demonstrated between SSc and RA regarding cIMT and Alx $75 \%(0.65$ vs $0,61 \mathrm{~mm} p=0,17$ and 33.4 vs $31,7 p=0,397$ respectively). However average QRisk3 score was significantly higher in the RA compared to the SSc group $(P<0.05)$.

Conclusion: The results of this comparative study show that subclinical atherosclerosis is comparable between individuals with SSc and RA, a systemic disease with well-defined high atherosclerotic burden. RA patients have higher CV risk (QRisk3 algorithm) suggesting that disease-specific factors such chronic high-grade inflammation may influence the $\mathrm{CV}$ risk in this population.

References:

[1] Ozen G, et al. Subclinical Atherosclerosis in Systemic Sclerosis: Not Less Frequent Than Rheumatoid Arthritis and Not Detected With Cardiovascular Risk Indices. Arthritis Care Res (Hoboken) 2016; 68:1538-46

[2] Pagkopoulou E, et al., Cardiovascular risk in systemic sclerosis: Micro- and Macro-vascular involvement. Indian J Rheumatol 2017;12: 211-7

Table 1. Demographic and cardiovascular risk factors of the matched patients

\begin{tabular}{lccc}
\hline & RA & SSc & P \\
\hline N=55 & $\mathbf{N = 5 5}$ & \\
\hline Age & $63.6(14.8)$ & $61.3(10.9)$ & 0.140 \\
Female & $49(89.1 \%)$ & $53(96.4 \%)$ & 0.438 \\
Smoking & $10(18.2 \%)$ & $13(23.6 \%)$ & 0.5 \\
Diabetes & $0(0.00 \%)$ & $1(1.82 \%)$ & 0.364 \\
Hyperlipidemia: & $7(12.7 \%)$ & $6(10.9 \%)$ & 1.000 \\
Hypertension: & $23(41.8 \%)$ & $19(34.5 \%)$ & 0.441 \\
ESRD & $20.4(18.4)$ & $22.0(19.1)$ & 0.666 \\
CRP & $8.38(11.6)$ & $6.65(30.2)$ & 0.692 \\
\hline
\end{tabular}

Table 2. Comparison of IMT, AIx75, Framingham and QRISK3 between matched patients

\begin{tabular}{lrrc}
\hline & RA & SSc & P \\
\hline & N=55 & N=55 & \\
\hline IMT right average & $0.65(0.17)$ & $0.61(0.12)$ & 0.175 \\
IMT left average & $0.67(0.15)$ & $0.64(0.13)$ & 0.214 \\
IMT average & $0.66(0.14)$ & $0.63(0.10)$ & 0.137 \\
AIX 75\% (\%) & $33.4(9.23)$ & $31.7(10.8)$ & 0.397 \\
Framingham risk & & & $<0.001$ \\
$<10 \%$ & $9(31.0 \%)$ & $37(74.0 \%)$ & \\
10-20\% & $12(41.4 \%)$ & $9(18.0 \%)$ & \\
$20-30 \%$ & $3(10.3 \%)$ & $4(8.00 \%)$ & $\mathbf{0 . 0 0 6}$ \\
$>30 \%$ & $5(17.2 \%)$ & $0(0.00 \%)$ & \\
QRISK3 & $18.2(15.3)$ & $11.1(10.6)$ & \\
\hline
\end{tabular}

Disclosure of Interests: Pantelis Baniotopoulos: None declared, Eleni Pagkopoulou: None declared, Stergios Soulaidopoulos: None declared, Aamer Sandoo: None declared, Niki Katsiki: None declared, Asterios Karagiannis: None declared, Karen Douglas: None declared, Alexandros Garyfallos Grant/research support from: MSD, Aenorasis SA, Speakers bureau: MSD, Novartis, gsk, Georeg Kitas: None declared, Theodoros Dimitroulas: None declared DOI: 10.1136/annrheumdis-2020-eular.2601

\section{CORRELATION BETWEEN PROGRESSION OF SKIN FIBROSIS AND PROGRESSION OF INTERSTITIAL LUNG DISEASE (ILD) IN PATIENTS WITH SSC-ILD: DATA FROM THE SENSCIS TRIAL}

O. Distler ${ }^{1}$, K. Highland ${ }^{2}$, A. M. Hoffmann-Vold ${ }^{3}$, O. Kowal-Bielecka ${ }^{4}$, U. Walker ${ }^{5}$, F. Del Galdo ${ }^{6}$, M. Vonk ${ }^{7}$, L. Hummers ${ }^{8}$, E. Erhardt ${ }^{9}$, M. Quaresma ${ }^{10}$, M. Alves ${ }^{10}$, V. Smith ${ }^{11}$. ${ }^{1}$ Department of Rheumatology, University Hospital Zurich, Zurich, Switzerland; ${ }^{2}$ Cleveland Clinic, Cleveland, Ohio, United States of America; ${ }^{3}$ Department of Rheumatology, 
Oslo University Hospital, Oslo, Norway; ${ }^{4}$ Department of Rheumatology and Internal Medicine, Medical University of Bialystok, Bialystok, Poland; ${ }^{5}$ Department of Rheumatology, University Hospital Basel, Basel, Switzerland; ${ }^{6}$ Leeds Institute of Rheumatic and Musculoskeletal Medicine and NIHR Biomedical Research Centre, University of Leeds, Leeds, United Kingdom; ${ }^{7}$ Department of Rheumatology, Radboud University Medical Center, Nijmegen, Netherlands; ${ }^{8}$ Division of Rheumatology, Johns Hopkins University School of Medicine, Baltimore, Maryland, United States of America; ${ }^{9}$ Mainanalytics ma GmbH, Sulzbach, Germany; ${ }^{10}$ Boehringer Ingelheim International GmbH, Ingelheim am Rhein, Germany; ${ }^{11}$ Department of Rheumatology, Ghent University Hospital, Ghent, Belgium; Department of Internal Medicine, Ghent University, Ghent, Belgium

Background: In the SENSCIS trial in patients with SSc-ILD, nintedanib reduced the rate of decline in FVC over 52 weeks vs placebo, with no difference between groups in change in mRSS.

Objectives: Analyse correlation between progression of skin fibrosis and progression of SSc-ILD in the SENSCIS trial.

Methods: Patients with SSC-ILD were randomised to receive nintedanib or placebo until the last patient reached week 52 but for $\leq 100$ weeks. We calculated Spearman correlation coefficients between FVC $(\mathrm{mL})$ at baseline and change from baseline in mRS, mRSS at baseline and change from baseline in FVC ( $\mathrm{mL})$, and changes from baseline in mRSS and FVC at weeks 52 and 100 in all patients. We analysed the rate of decline in FVC ( $\mathrm{mL} /$ year) in patients who did and did not have progression of skin fibrosis (relative change from baseline in $\mathrm{mRSS}>25 \%$ and absolute change from baseline $>5$ points) at week 52 .

Results: In the nintedanib $(n=288)$ and placebo $(n=288)$ groups, respectively, mean (SD) baseline FVC (mL) was 2459 (736) and 2541 (816) and mRSS was 11.3 (9.2) and 10.9 (8.8); 53.1\% and 50.7\% had dcSSc; $18.4 \%$ and $16.0 \%$ had progression of mRSS at week 52 . No meaningful correlations were observed in analyses between mRSS and FVC (Table). The mean (SE) annual rate of decline in FVC in the placebo group was similar in patients who did and did not have progression of mRSS (-95.2 [27.1] and -91.4 [15.7] mL/year, respectively). The effect of nintedanib vs placebo on reducing the rate of decline in FVC was numerically more pronounced in patients who did not have progression of mRSS vs those who did (difference [95\% Cl] $44.3 \mathrm{~mL} /$ year $[0.6,88.1]$ vs $24.6[-53.7,102.9]$ ), but the interaction $p$-value $(0.66)$ did not indicate heterogeneity in treatment effect between subgroups.

Conclusion: In the SENSCIS trial, the proportion of patients who had progression of skin fibrosis over 52 weeks was low, without significant differences between placebo and nintedanib. No meaningful correlations were observed between skin fibrosis at baseline or progression of skin fibrosis and progression of SSc-ILD. The rate of decline in FVC was similar between patients who did and did not have progression of mRSS. These findings suggest that in the overall patient population in the SENSCIS trial, progression of skin fibrosis and progression of ILD were distinct manifestations of disease progression.

Table:

\begin{tabular}{|c|c|c|c|c|c|c|}
\hline & \multicolumn{2}{|c|}{$\begin{array}{l}\text { FVC at baseline and } \\
\text { change from baseline } \\
\text { in mRSS }\end{array}$} & \multicolumn{2}{|c|}{$\begin{array}{l}\text { mRSS at baseline and } \\
\text { change from baseline } \\
\text { in FVC }\end{array}$} & \multicolumn{2}{|c|}{$\begin{array}{l}\text { Changes from } \\
\text { baseline in mRSS } \\
\text { and FVC }\end{array}$} \\
\hline & $\mathrm{N}$ & Correlation* & $\mathbf{N}$ & Correlation* & $\mathbf{N}$ & Correlation* \\
\hline \multicolumn{7}{|l|}{ Week 52} \\
\hline Nintedanib & 247 & $\begin{array}{l}0.11(-0.01 \\
0.23)\end{array}$ & 241 & $\begin{array}{c}-0.08(-0.20 \\
0.05)\end{array}$ & 238 & $\begin{array}{c}-0.07(-0.19 \\
0.06)\end{array}$ \\
\hline Placebo & 254 & $\begin{array}{l}0.12(-0.00 \\
0.24)\end{array}$ & 257 & $\begin{array}{c}-0.15(-0.27 \\
-0.03)\end{array}$ & 252 & $\begin{array}{c}0.03(-0.09 \\
0.15)\end{array}$ \\
\hline \multicolumn{7}{|l|}{ Week 100} \\
\hline Nintedanib & 73 & $\begin{array}{l}0.21(-0.02 \\
0.42)\end{array}$ & 73 & $\begin{array}{c}-0.06(-0.29 \\
0.17)\end{array}$ & 70 & $\begin{array}{c}0.06(-0.17 \\
0.30)\end{array}$ \\
\hline Placebo & 66 & $\begin{array}{c}0.28(0.04 \\
0.49)\end{array}$ & 73 & $\begin{array}{c}0.04(-0.19 \\
0.27)\end{array}$ & 66 & $\begin{array}{c}-0.14(-0.37 \\
0.10)\end{array}$ \\
\hline
\end{tabular}

${ }^{*}$ Spearman correlation coefficient $(95 \% \mathrm{Cl})$

Disclosure of Interests: Oliver Distler Grant/research support from: Grants/ Research support from Actelion, Bayer, Boehringer Ingelheim, Competitive Drug Development International Ltd. and Mitsubishi Tanabe; he also holds the issued Patent on mir-29 for the treatment of systemic sclerosis (US8247389, EP2331143)., Consultant of: Consultancy fees from Actelion, Acceleron Pharma, AnaMar, Bayer, Baecon Discovery, Blade Therapeutics, Boehringer, CSL Behring, Catenion, ChemomAb, Curzion Pharmaceuticals, Ergonex, Galapagos NV, GSK, Glenmark Pharmaceuticals, Inventiva,
Italfarmaco, iQvia, medac, Medscape, Mitsubishi Tanabe Pharma, MSD, Roche, Sanofi and UCB, Speakers bureau: Speaker fees from Actelion, Bayer, Boehringer Ingelheim, Medscape, Pfizer and Roche, Kristin Highland Grant/research support from: Boehringer Ingelheim - PI for SENS CIS and SENSCIS-ON trials (paid to my institution), Consultant of: Kristin Highland has acted as a consultant to Boehringer Ingelheim. She was a member of the SENSCIS trial Steering Committee (Boehringer Ingelheim), Speakers bureau: Kristin Highland reports speaker fees from Boehringer Ingelheim, Anna-Maria Hoffmann-Vold Grant/research support from Boehringer Ingelheim, Consultant of: Boehringer Ingelheim, Actelion, Bayer, GlaxoSmithKline, Speakers bureau: Boehringer Ingelheim, Actelion, Roche, Otylia Kowal-Bielecka Grant/research support from: Boehringe Ingelheim, Consultant of: Boehringer Ingelheim, Inventiva, MSD, Novartis Speakers bureau: Boehringer Ingelheim, Medac, Novartis, Roche, Sandoz, Ulrich Walker Grant/research support from: Ulrich Walker has received an unrestricted research grant from Abbvie, Consultant of: Ulrich Walker has act as a consultant for Abbvie, Actelion, Boehringer Ingelheim, Bristol-Myers Squibb, Celgene, MSD, Novartis, Pfizer, Phadia, Roche, Sandoz, Sanofi, and ThermoFisher, Paid instructor for: Abbvie, Novartis, and Roche, Speakers bureau: Abbvie, Actelion, Bristol-Myers Squibb, Celgene, MSD Novartis, Pfizer, Phadia, Roche, Sandoz, and ThermoFisher, Francesco Del Galdo: None declared, Madelon Vonk Grant/research support from: Janssen and Ferrer, Consultant of: Boehringer Ingelheim, Janssen and GSK, Speakers bureau: Boehringer Ingelheim, BMS and Roche, Laura Hummers Grant/research support from: Boehringer Ingleheim, Corbus pharmaceuticals, CSL Behring, Cumberland Pharmaceuticals, and GlaxoSmithKline, Consultant of: Boehringer Ingleheim, Corbus pharmaceuticals, and CSL Behring, Elvira Erhardt Employee of: Employee of Boehringer Ingelheim, Manuel Quaresma Employee of: Employee of Boehringer Ingelheim, Margarida Alves Employee of: Employee of Boehringer Ingelheim, Vanessa Smith Grant/research support from: The affiliated company received grants from Research Foundation - Flanders (FWO), Belgian Fund for Scientific Research in Rheumatic diseases (FWRO), Boehringer Ingelheim Pharma $\mathrm{GmbH} \& \mathrm{Co}$ and Janssen-Cilag NV, Consultant of: Boehringer-Ingelheim Pharma $\mathrm{GmbH}$ \& Co, Speakers bureau: Actelion Pharmaceuticals Ltd, Boehringer-Ingelheim Pharma GmbH \& Co and UCB Biopharma Sprl DOI: 10.1136/annrheumdis-2020-eular.2887

\section{SAT0314 \\ TIMED FUNCTION TESTS ARE AN ALTERNATIVE TO MMT8 AND FI-2 IN INFLAMMATORY MYOSITIS - AN OBSERVATIONAL COHORT STUDY}

S. K. Dunga ${ }^{1}$, A. M B ${ }^{2}$, C. Kavadichanda ${ }^{2}$, V. Negi ${ }^{3}{ }^{1}$ Jawaharlal Institute of Postgraduate Medical Education and Research, Clinical Immunology, Puducherry, India; ${ }^{2}$ Jawaharlal Institute of Postgraduate Medical Education and Research, Puducherry, India; ${ }^{3}$ Jawaharlal Institute of Postgraduate Medical Education and Research, Puducherry, India

Background: Inflammatory myositis are heterogenous group of diseases affecting skeletal muscles and multiple different organs ${ }^{1}$. Manual muscle testing (MMT) is the common tool used for assessment of muscle strength. Its limitations include poor sensitivity to change, floor/ceiling effect, and under representation of certain important muscle groups ${ }^{2}$. Functional index $2(\mathrm{FI}-2)$ is an objective measure of dynamic repetitive muscle function at 11 proximal and distal muscle groups which correlates well with patient-reported physical function ${ }^{3}$. Since MMT8 is inadequate and FI-2 takes longer time to administer, several timed tests to assess muscle function, endurance and fatiguability like the 2- minute walk test (2MWT) or 30s raise from a chair test and 30 s arm rise test are viable alternatives to be tested. Data looking at the performance of these tests are limited to small controlled studies.

Objectives: To study correlation of timed tests with MMT8 and FI-2 in assessing muscle strength, endurance at baseline and at 3 months of therapy.

Methods: An observational cohort study, included 19 patients with polymyositis and dermatomyositis attending OPD and IPD service of tertiary center. Patients with nclusion body myositis, overlap myositis, chronic kidney disease, coexisting myocarditis, sepsis, malignancy, pregnancy were excluded. MMT8, FI-2 and Timed function tests were done at baseline and after 3 months.

Results: The study had 19 patients of which 6 were polymyositis and 13 were dermatomyositis. Male to female ratio was 1:2.1. Anti-cell antibody was positive in 16 patients. The mean MMT8 of the study group at baseline was $60.84 \pm 16.77$ and after 3 months was $67.05 \pm 11.7$. Out of 19 patients, all received prednisolone as induction agent followed by Methotrexate in 13, cyclophosphamide in 9, azathioprine in 5, Rituximab by one patient. Mean scores of $30 \mathrm{~s}$ arm lift, $30 \mathrm{~s}$ rise from chair test and $2 \mathrm{~min}$ walk test were $11.7 \pm 6.39,14 \pm 7.29,101.5 \pm 46.48$ respectively at baseline and $13.05 \pm 6.5,15.6 \pm 7.1,117.84 \pm 38.4$ after 3 months. 